\title{
Article \\ Combined Multimorbidity and Polypharmacy Patterns in the Elderly: A Cross-Sectional Study in Primary Health Care
}

\author{
Grant Stafford 1,2 , Noemí Villén ${ }^{3,4}$, Albert Roso-Llorach 2,4,5, Amelia Troncoso-Mariño ${ }^{3,6}$, Mònica Monteagudo ${ }^{2,5}$ \\ and Concepción Violán $5,7, *$
}

1 Programa de Máster en Salud Pública, Universitat Pompeu Fabra, 08003 Barcelona, Spain; grant.stafford95@gmail.com

2 Unitat Transversal de Recerca (UTR), Fundació Institut Universitari per a la Recerca a l'Atenció Primària de Salut Jordi Gol i Gurina (IDIAPJGol), 08007 Barcelona, Spain; aroso@idiapjgol.org (A.R.-L.); mmonteagudo@idiapjgol.org (M.M.)

3 Àrea del Medicament i Servei de Farmàcia, Atenció Primària Barcelona Ciutat, Institut Català de la Salut (ICS), 08015 Barcelona, Spain; nvillenr.bcn.ics@gencat.cat (N.V.); atroncoso@gencat.cat (A.T.-M.)

4 Programa de Doctorat en Metodologia de la Recerca Biomèdica i Salut Pública, Universitat Autònoma de Barcelona, Bellaterra (Cerdanyola del Vallès), 08193 Barcelona, Spain

5 Universitat Autònoma de Barcelona, Bellaterra (Cerdanyola del Vallès), 08193 Barcelona, Spain

6 Department of Clinical Sciences, University of Barcelona and IDIBELL, L'Hospitalet de Llobregat, 08907 Barcelona, Spain

Citation: Stafford, G.; Villén, N.; Roso-Llorach, A.; Troncoso-Mariño, A.; Monteagudo, M.; Violán, C. Combined Multimorbidity and Polypharmacy Patterns in the Elderly: A Cross-Sectional Study in Primary Health Care. Int. J. Environ. Res. Public Health 2021, 18, 9216. https:// doi.org/10.3390/ijerph18179216

Academic Editors: Belchin Kostov, Luis González-de Paz and Antoni Sisó-Almirall

Received: 22 June 2021

Accepted: 26 August 2021

Published: 1 September 2021

Publisher's Note: MDPI stays neutral with regard to jurisdictional claims in published maps and institutional affiliations.

Copyright: (c) 2021 by the authors. Licensee MDPI, Basel, Switzerland. This article is an open access article distributed under the terms and conditions of the Creative Commons Attribution (CC BY) license (https:// creativecommons.org/licenses/by/ $4.0 /)$.
7 Unitat de Suport a la Recerca Metropolitana Nord, Fundació Institut Universitaria per a la Recerca a l'Atenció Primària de Salut Jordi Gol i Gurina (IDIAPJGol), 08303 Mataró, Spain

* Correspondence: cviolanf.mn.ics@gencat.cat

Abstract: (1) Background: The acquisition of multiple chronic diseases, known as multimorbidity, is common in the elderly population, and it is often treated with the simultaneous consumption of several prescription drugs, known as polypharmacy. These two concepts are inherently related and cause an undue burden on the individual. The aim of this study was to identify combined multimorbidity and polypharmacy patterns for the elderly population in Catalonia. (2) Methods: A cross-sectional study using electronic health records from 2012 was conducted. A mapping process was performed linking chronic disease categories to the drug categories indicated for their treatment. A soft clustering technique was then carried out on the final mapped categories. (3) Results: 916,619 individuals were included, with $93.1 \%$ meeting the authors' criteria for multimorbidity and $49.9 \%$ for polypharmacy. A seven-cluster solution was identified: one non-specific (Cluster 1) and six specific, corresponding to diabetes (Cluster 2), neurological and musculoskeletal, female dominant (Clusters 3 and 4) and cardiovascular, cerebrovascular and renal diseases (Clusters 5 and 6), and multisystem diseases (Cluster 7). (4) Conclusions: This study utilized a mapping process combined with a soft clustering technique to determine combined patterns of multimorbidity and polypharmacy in the elderly population, identifying overrepresentation in six of the seven clusters with chronic disease and chronic disease-drug categories. These results could be applied to clinical practice guidelines in order to better attend to patient needs. This study can serve as the foundation for future longitudinal regarding relationships between multimorbidity and polypharmacy.

Keywords: multimorbidity; polypharmacy; elderly; primary healthcare; chronic disease; clustering; combined patterns; machine learning

\section{Introduction}

The global life expectancy at birth has increased from 52.6 years in 1960 to 72.6 years in 2018 [1]. While it is certain that people are living longer on average, this does not necessarily mean they are living healthier lives, as an increase in life expectancy anticipates an increase in morbidity [2,3]. As individuals age, the body changes and experiences a state of physical decline, resulting in weaker defenses and easier acquisition of chronic 
illnesses in the later years of life [2,4]. The diagnosis of two or more chronic diseases in the same individual is referred to as multimorbidity [5].

Multimorbid individuals tend to be prescribed a high number of medications in order to combat their diagnosed chronic illnesses. Consumption of prescribed drugs holds a higher prevalence and relevance in older adults, and complications could include potentially inappropriate prescribing [6]. While a homogeneous operational definitional is lacking throughout the field, literature supports the definition of polypharmacy as the consumption of five or more drugs daily in the same individual [7]. Polypharmacy is considered a critical public health problem that is related to drug-drug and drug-disease interactions, adverse drug events [8-12], falls, hospital admissions and mortality [13,14]. Polypharmacy has been on the rise over the past several decades [11] and is highly associated to multimorbidity [8].

In a world with an ageing population, the burdens of multimorbidity and polypharmacy have undue individual and system-wide impacts on health. While there exists a growing amount of literature regarding multimorbidity and polypharmacy, the vast majority of studies analyze polypharmacy as descriptive drugs in multimorbidity patterns, focus almost exclusively on one topic or the other without meaningfully connecting the two, or examine the disease rather than the individual as the unit of analysis [15-17]. Furthermore, medication is considered a proxy variable to disease $[15,18,19]$, and, for this reason, jointly analyzing multimorbidity and polypharmacy can produce an overestimation error due to the fact that people with prevalent diseases such as diabetes or cardiovascular diseases are treated with many medications for both clinical conditions and risk factors and, for this reason, are overestimated. To avoid this, drug groups can be analyzed according to their associated disease, thereby preventing prevalent diseases from being overestimated. This type of approach would permit a better understanding of the patient groups and, at the same time, facilitate strategies aimed at prevention, diagnosis, and treatment because it includes diseases with or without drug treatment.

As far as we understand, little research has been completed regarding methods that simultaneously analyze the combined patterns of multimorbidity and polypharmacy at an individual level. Machine-learning soft clustering models are a robust tool capable of performing such an analysis. Cluster analysis involves assigning individuals to a certain cluster so that the items (i.e., units of analysis-diseases and drugs) are as similar as possible, while individuals in different clusters are as least similar as possible. Cluster identification is based on similarity measures, and their choice is reliant upon the data and/or the reason for analysis [20]. Hard clustering forces each individual to belong to only one cluster, while soft clustering (also called fuzzy clustering) grants varying degrees of membership, thus allowing for the individual to pertain to multiple clusters [20]. The aim of this study was to determine combined patterns of multimorbidity and polypharmacy in the Catalan population 65-99 years of age through a machine-learning soft clustering technique that incorporates the research team's mapping of chronic disease and drug associations.

\section{Materials and Methods}

\subsection{Setting, Design, and Population}

Catalonia, an autonomous community of Spain, is a Mediterranean region with $7,515,398$ reported inhabitants for the year 2012 [21]. Universal health coverage is established for residents in Spain by the National Health Service and is implemented in a decentralized fashion through each of the seventeen autonomous communities [22]. In Catalonia, the Catalan Health Institute (CHI) manages over 283 primary care centers, offering health services to over six million residents [23].

A cross-sectional study was performed on the baseline year (2012) of a longitudinal study (2012-2016) using electronic health records (EHRs) in Catalonia. Inclusion criteria for the cross-sectional study population allowed for individuals 65-99 years of age on 31 December 2011, who survived until 31 December 2012, and had at least one visit to 
a CHI-managed primary care center during the longitudinal study period (2012-2016). No new entries were permitted in the study, and dropouts were due to either death or transfer to another primary care center outside of $\mathrm{CHI}$ governance. A total of 916,619 eligible individuals were included at the baseline year (Figure 1).

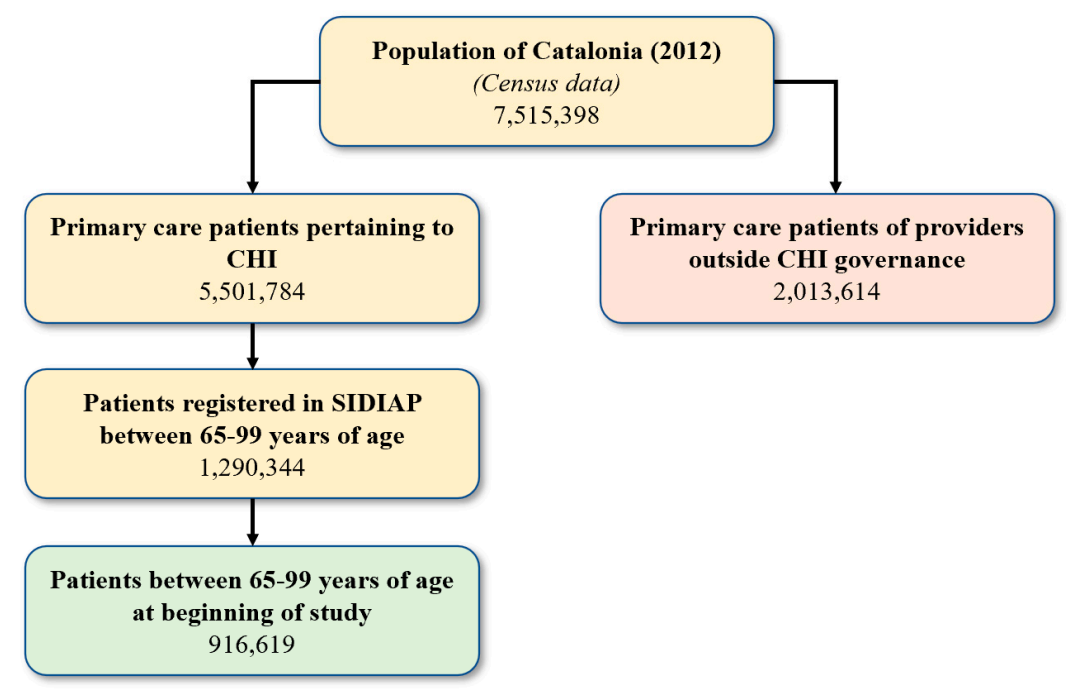

Figure 1. Estimated population study according to selection criteria.

\subsection{Data Source}

The Information System for Research in Primary Care (SIDIAP) contains EHRs from the primary care centers managed by the $\mathrm{CHI}$ [24]. The SIDIAP database, in addition to clinical information, contains demographic, laboratory, and invoiced drug information, with every datapoint linked to the individual via an anonymous and unique personal identifier.

\subsection{Variables}

The SIDIAP database was the single source of information for all variables. All variables were analyzed exclusively within the study period (2012).

\subsubsection{Chronic Diseases and Multimorbidity}

All diseases in the SIDIAP database were coded according to the International Classification of Diseases, Version 10 (ICD-10). An operational definition for multimorbidity was based on the 60 chronic disease categories determined by Calderón-Larrañaga et al. in the Swedish National study of Aging and Care in Kungsholmen (SNAC-K) [25]. Each chronic disease category was included as an individual binary variable, and multimorbidity was defined via a dichotomous variable as the presence of two or more diagnoses from the 60 chronic disease categories. However, only chronic disease categories with $\geq 2 \%$ prevalence in the study population were included for final analysis, thus leaving 47 SNAC-K chronic disease categories in total (Appendix A Table A1).

\subsubsection{Drugs and Classification}

Invoiced drugs recorded in the SIDIAP database included drugs dispensed in pharmacies. Drugs received in hospital and/or dispensed by a hospital pharmacy and all other drugs not subsidized through the national health system were excluded from this study. Drugs were coded according to the Anatomical Therapeutic Chemical (ATC) Classification System, which categorizes drugs through various levels of specificity into groups (hereafter referred to as "drug categories") according to the targeted organ/system and their chemical, pharmacological, and therapeutic properties [26]. Drug categories with $\geq 1 \%$ prevalence in the study population were included for final analysis. Chronic use for invoiced drugs 
was determined for individuals who were invoiced three or more packages of the same drug categories during the study period. While not meeting the prevalence or chronic use criteria, the drug category Other Drugs Affecting Bone Structure and Mineralization (ATC 4th level code "M05BX") was added to the study due to its twice-a-year treatment regimen for chronic diseases. Each drug category was included as an individual binary variable, and polypharmacy was defined via a dichotomous variable as chronic use in the same individual for five or more different drug categories (ATC 4th level) from the eighty-nine drug categories outlined in the following section.

\subsubsection{Grouping of Drugs and Mapping to Chronic Diseases}

The research team identified 89 different drug categories (ATC 4th level) (Appendix A Table A2) associated to the 60 chronic disease categories mentioned prior via a thorough revision of several databases that are well-known international clinical guidelines for each disease [27-29]. A mapping was done of all 60 SNAC-K chronic disease categories [25] and 89 drug categories. Drug categories were mapped to the SNAC-K chronic disease categories for which they are prescribed to treat. Chronic disease-drug categories were then created in the form of dichotomous variables for individuals who were diagnosed with a SNAC-K chronic disease category and, depending on disease management criteria, invoiced 0,1 , or 1+ of the mapped drug categories. (For example, the Allergy disease category was mapped with seven drug categories. An individual would qualify in this category if diagnosed with a disease pertaining to the Allergy disease category and invoiced at least one of the seven drug categories). A total of seven of the final 47 SNAC-K chronic diseases categories require non-pharmacological treatments or treatment with drugs excluded from this study and, therefore, could not be mapped. The remaining 40 SNAC-K chronic disease categories were mapped to drug categories, resulting in 29 chronic disease-drug categories containing $\geq 2 \%$ prevalence in the study population (see Appendix A Table A3 for mapping example; see Supplementary Materials Table S1 for complete mapping process). The seven chronic disease categories requiring non-pharmacological treatment or treatment with drugs excluded from this study and the 29 chronic disease-drug categories, all with prevalence $\geq 2 \%$, were included to determine combined patterns of multimorbidity and polypharmacy (Figure 2).

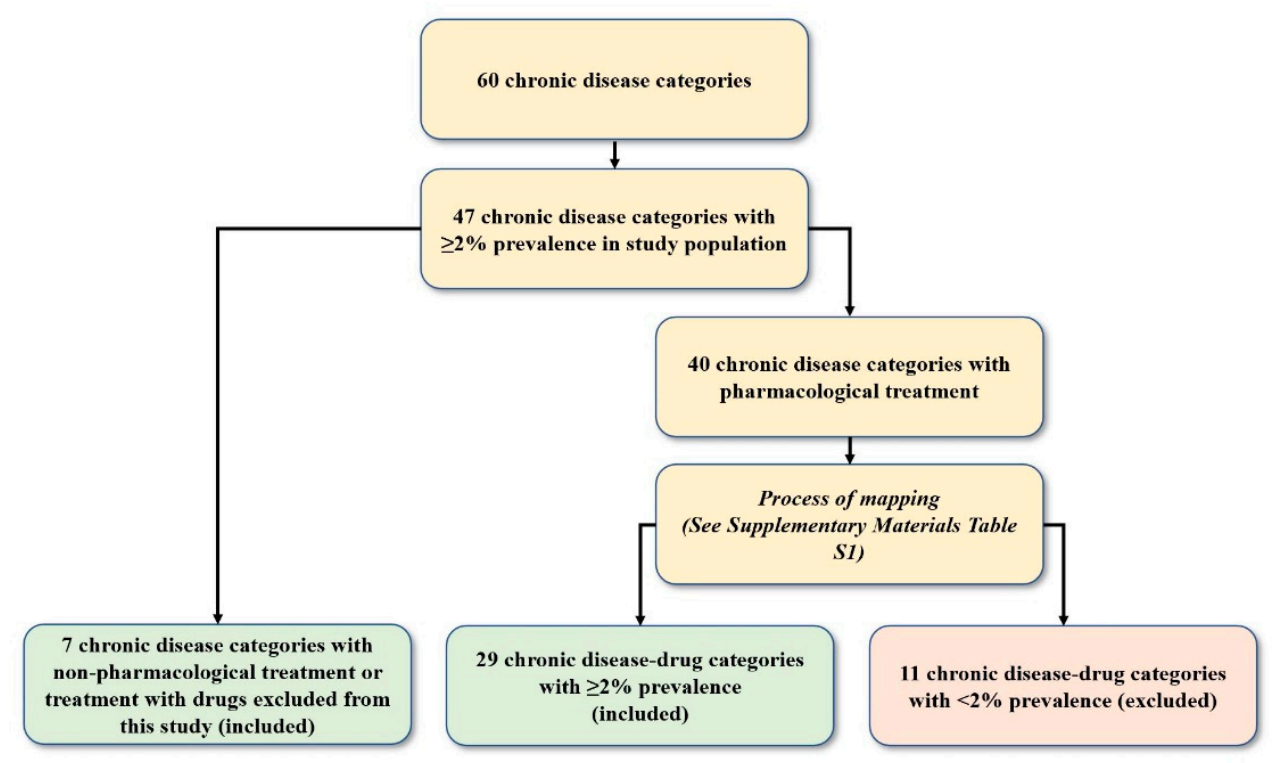

Figure 2. Number of significant chronic disease or chronic disease-drug categories after mapping.

\subsubsection{Other Variables}

Pertinent demographic data analyzed in the study includes age (measured in years), sex (female or male), and socioeconomic status (measured by the MEDEA [Mortality 
in Spanish Small Areas and Socioeconomic and Environmental Inequalities] Index via quintiles from least deprived to most deprived for urban areas, while rural areas were sorted into an independent category [30]).

\subsection{Statistical Analysis}

Descriptive statistics were applied to summarize preliminary findings.

Due to the high dimensionality of the SIDIAP database, dimension-reduction techniques were exercised through PCA Mix, an application of principal component analysis (PCA) for numeric original variables and multiple correspondence analysis (MCA) for binary variables. This method reduced the size of the database while maintaining the complexity of the original data. The Karlis-Saporta-Spinaki rule was applied in order to select the appropriate number of dimensions to preserve [31].

Using the reduced database, the combined multimorbidity and polypharmacy patterns were determined through a fuzzy c-means (FCM) clustering algorithm [32], incorporating the twenty-nine chronic disease-drug categories and the seven chronic disease categories with non-pharmacological treatment or treatment with drugs excluded from this study, all of which satisfied the prevalence threshold of $\geq 2 \%$ in the study population. To obtain a range with the ideal number of clusters, validation indices [33] were calculated (Supplementary Materials Figure S1). The outcome of the FCM clustering algorithm was a determined number of models with different numbers of clusters in each model, as calculated by the validation indices. Each model contained varying degrees of disease-medication association, and the final model of clusters was determined by the research team according to clinical relevance.

The clusters were described in two parts: (1) observed/expected ratios $(\mathrm{O} / \mathrm{E}$ ratios) were calculated by dividing the prevalence of a chronic disease or chronic disease-drug category in a specific cluster by the prevalence of the same chronic disease or chronic disease-drug category in the entire study population; (2) exclusivity was determined by dividing the number of individuals with a chronic disease or chronic disease-drug category in a specific cluster by the amount of all individuals with the same chronic disease or chronic disease-drug category in the entire study population. A threshold of two for the $\mathrm{O} / \mathrm{E}$ ratio was set in order for a disease/medication to be considered a relevant part of a cluster $[34,35]$. An exclusivity threshold of $30 \%$ was a secondary, but not determining, factor when evaluating the chronic disease or chronic disease-drug categories association with a cluster.

All analyses were performed in $\mathrm{R}$ version 4.0 .3 and Stata version 15. Specifically, $\mathrm{R}$ was used to run the PCA mix and FCM clustering algorithm; Stata was used for data management.

\section{Results}

Of the 916,619 eligible individuals 65 years and over (women: $57.8 \%$; mean age: 75.4; standard deviation; 7.4), 853,085 (93.1\%) satisfied the criteria for multimorbidity, and $457,576(49.9 \%)$ for polypharmacy (Figure 3). The most frequent chronic disease categories in the population were hypertension (71\%), dyslipidemia (50.9\%), osteoarthritis and other degenerative joint diseases $(32.8 \%)$, obesity $(28.7 \%)$, and diabetes $(25.1 \%)$ [Appendix A Table A1], with a median of six chronic diseases (interquartile range [IQR] 4.0-8.0) per person. The most prevalent drug categories included proton pump inhibitors (44.3\%), HMG CoA reductase inhibitors (38.2\%), anilides $(28.4 \%)$, platelet aggregation inhibitors, excluding heparin (35.6\%), and benzodiazepine derivatives (20.9\%) [Appendix A Table A2], with a median of 5 drugs (IQR 2.0-8.0) per person. 


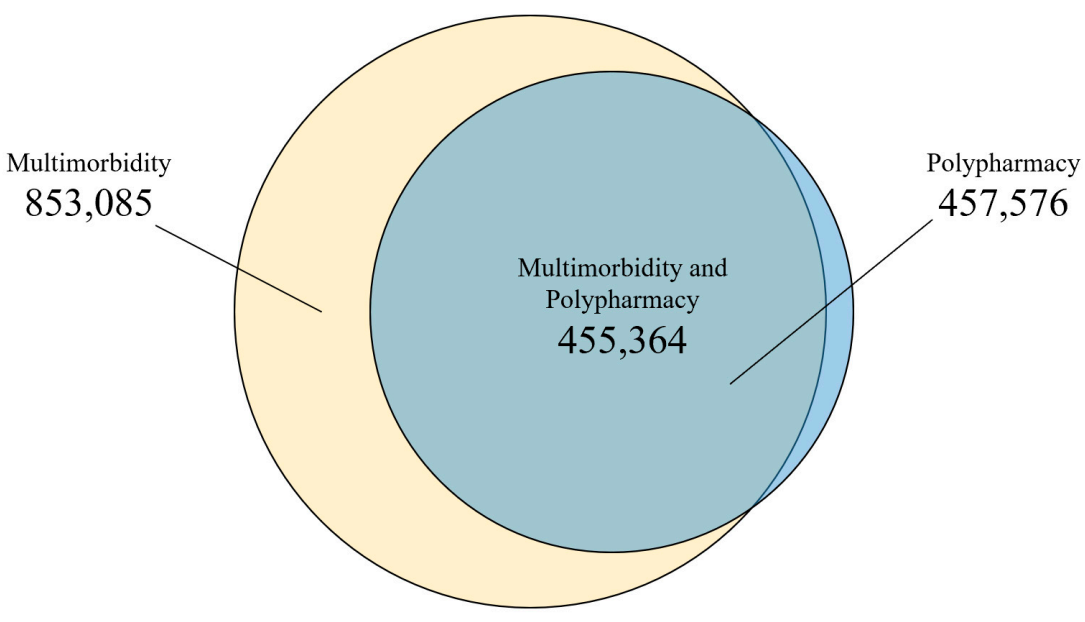

Figure 3. Multimorbid and polymedicated individuals in the study aged 65-99 years $(n=916,619$, Catalonia, 2012).

The authors identified a seven-cluster solution for combined patterns of multimorbidity and polypharmacy. Cluster 2 to Cluster 7 contained over $99 \%$ multimorbidity in each cluster and reported higher overrepresentation values $(\mathrm{O} / \mathrm{E}$ ratio $>2)$ for at least one of the chronic disease or chronic disease-drug categories. Characteristics of the study participants in each cluster are detailed in Appendix A Table A4. Principal results and the most frequent chronic disease and chronic disease-drug categories by cluster (Table 1) are highlighted below:

Table 1. Most frequent 15 chronic disease or chronic disease-drug categories in individuals aged 65-99 years by cluster ( $n=916,619$, Catalonia, 2012).

\begin{tabular}{|c|c|c|c|c|}
\hline Pattern & Disease or Disease-Medication Category & $\mathbf{O}$ & O/E Ratio & EX \\
\hline \multirow{15}{*}{$\begin{array}{c}1 \\
\text { Non-Specific } \\
(n=344,958: 37.63 \%)\end{array}$} & Chronic disease group for solid neoplasms & 12.86 & 0.86 & 32.37 \\
\hline & Chronic disease-drug group for prostate diseases & 7.82 & 0.77 & 29.11 \\
\hline & Chronic disease-drug group for osteoporosis & 7.74 & 0.74 & 27.74 \\
\hline & Chronic disease group for deafness and hearing loss & 5.91 & 0.60 & 22.58 \\
\hline & $\begin{array}{l}\text { Chronic disease-drug group for COPD, emphysema, and chronic } \\
\text { bronchitis }\end{array}$ & 4.26 & 0.53 & 20.03 \\
\hline & 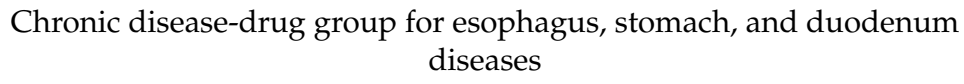 & 3.77 & 0.52 & 19.54 \\
\hline & Chronic disease-drug group for thyroid diseases & 2.84 & 0.51 & 19.34 \\
\hline & Chronic disease group for cataract and lens diseases & 8.47 & 0.50 & 18.65 \\
\hline & Chronic disease-drug group for dementia & 1.56 & 0.47 & 17.61 \\
\hline & Chronic disease-drug group for hypertension & 26.41 & 0.46 & 17.48 \\
\hline & Chronic disease group for bradycardias and conduction diseases & 1.12 & 0.40 & 15.13 \\
\hline & Chronic disease-drug group for sleep disorders & 2.22 & 0.39 & 14.64 \\
\hline & Chronic disease group for obesity & 11.29 & 0.39 & 14.82 \\
\hline & Chronic disease-drug group for dyslipidemia & 12.32 & 0.38 & 14.40 \\
\hline & $\begin{array}{l}\text { Chronic disease group for chronic pancreas, biliary tract, and } \\
\text { gallbladder diseases }\end{array}$ & 1.09 & 0.37 & 13.78 \\
\hline
\end{tabular}


Table 1. Cont.

\begin{tabular}{|c|c|c|c|c|}
\hline Pattern & Disease or Disease-Medication Category & $\mathbf{O}$ & O/E Ratio & EX \\
\hline \multirow{15}{*}{$\begin{array}{c}2 \\
\text { Diabetes } \\
(n=178,457: 19.47 \%)\end{array}$} & Chronic disease-drug group for diabetes & 39.52 & 2.15 & 41.93 \\
\hline & Chronic disease-drug group for glaucoma & 10.75 & 1.78 & 34.65 \\
\hline & Chronic disease group for obesity & 49.61 & 1.73 & 33.68 \\
\hline & Chronic disease-drug group for dyslipidemia & 55.12 & 1.71 & 33.33 \\
\hline & Chronic disease-drug group for hypertension & 84.37 & 1.48 & 28.89 \\
\hline & Chronic disease-drug group for thyroid diseases & 7.44 & 1.34 & 26.17 \\
\hline & Chronic disease-drug group for chronic kidney diseases & 13.92 & 1.32 & 25.69 \\
\hline & Chronic disease-drug group for ischemic heart disease & 8.52 & 1.11 & 21.61 \\
\hline & Chronic disease-drug group for cerebrovascular diseases & 6.54 & 1.01 & 19.69 \\
\hline & Chronic disease group for cataract and lens diseases & 17.15 & 1.00 & 19.54 \\
\hline & Chronic disease-drug group for peripheral vascular disease & 2.55 & 1.00 & 19.47 \\
\hline & Chronic disease-drug group for prostate diseases & 9.58 & 0.95 & 18.46 \\
\hline & Chronic disease group for solid neoplasms & 14.06 & 0.94 & 18.31 \\
\hline & Chronic disease group for deafness and hearing loss & 8.42 & 0.85 & 16.64 \\
\hline & $\begin{array}{c}\text { Chronic disease group for chronic pancreas, biliary tract, and } \\
\text { gallbladder diseases }\end{array}$ & 2.40 & 0.80 & 15.67 \\
\hline \multirow{15}{*}{$\begin{array}{c}3 \\
\text { Neurological and } \\
\text { Musculoskeletal, } \\
\text { Female Dominant } \\
(n=102,750: 11.21 \%)\end{array}$} & Chronic disease-drug group for peripheral neuropathy & 9.73 & 3.08 & 34.56 \\
\hline & Chronic disease-drug group for dorsopathies & 24.05 & 2.88 & 32.24 \\
\hline & $\begin{array}{l}\text { Chronic disease-drug group for other musculoskeletal and joint } \\
\text { diseases }\end{array}$ & 22.42 & 2.73 & 30.64 \\
\hline & Chronic disease-drug group for other genitourinary diseases & 8.68 & 2.44 & 27.32 \\
\hline & Chronic disease-drug group for glaucoma & 14.68 & 2.43 & 27.25 \\
\hline & $\begin{array}{c}\text { Chronic disease-drug group for osteoarthritis and other } \\
\text { degenerative joint diseases }\end{array}$ & 41.87 & 2.16 & 24.19 \\
\hline & Chronic disease group for deafness and hearing loss & 19.68 & 2.00 & 22.40 \\
\hline & $\begin{array}{l}\text { Chronic disease-drug group for neurotic, stress-related, and } \\
\text { somatoform diseases }\end{array}$ & 20.38 & 1.99 & 22.36 \\
\hline & Chronic disease group for cataract and lens diseases & 33.75 & 1.98 & 22.14 \\
\hline & Chronic disease-drug group for depression and mood diseases & 23.16 & 1.86 & 20.90 \\
\hline & Chronic disease-drug group for osteoporosis & 18.91 & 1.80 & 20.17 \\
\hline & Chronic disease-drug group for colitis and related diseases & 18.22 & 1.79 & 20.09 \\
\hline & Chronic disease-drug group for sleep disorders & 9.93 & 1.74 & 19.51 \\
\hline & $\begin{array}{c}\text { Chronic disease-drug group for other psychiatric and behavioral } \\
\text { diseases }\end{array}$ & 3.18 & 1.58 & 17.71 \\
\hline & $\begin{array}{c}\text { Chronic disease-drug group for esophagus, stomach, and duodenum } \\
\text { diseases }\end{array}$ & 11.29 & 1.55 & 17.41 \\
\hline
\end{tabular}


Table 1. Cont.

\begin{tabular}{|c|c|c|c|c|}
\hline Pattern & Disease or Disease-Medication Category & $\mathbf{O}$ & O/E Ratio & EX \\
\hline \multirow{15}{*}{$\begin{array}{c}4 \\
\text { Behavioral, } \\
\text { Neurological, and } \\
\text { Musculoskeletal, } \\
\text { Female Dominant } \\
(n=90,287: 9.85 \%)\end{array}$} & $\begin{array}{l}\text { Chronic disease-drug group for other psychiatric and behavioral } \\
\text { diseases }\end{array}$ & 7.42 & 3.69 & 36.34 \\
\hline & $\begin{array}{c}\text { Chronic disease-drug group for neurotic, stress-related, and } \\
\text { somatoform diseases }\end{array}$ & 37.33 & 3.65 & 36.00 \\
\hline & Chronic disease-drug group for peripheral neuropathy & 10.93 & 3.46 & 34.09 \\
\hline & Chronic disease-drug group for depression and mood diseases & 41.75 & 3.36 & 33.10 \\
\hline & Chronic disease-drug group for dorsopathies & 27.22 & 3.25 & 32.06 \\
\hline & $\begin{array}{l}\begin{array}{c}\text { Chronic disease-drug group for other musculoskeletal and joint } \\
\text { diseases }\end{array}\end{array}$ & 26.65 & 3.25 & 32.00 \\
\hline & Chronic disease-drug group for other genitourinary diseases & 9.81 & 2.76 & 27.14 \\
\hline & Chronic disease-drug group for sleep disorders & 15.07 & 2.64 & 26.02 \\
\hline & $\begin{array}{c}\text { Chronic disease-drug group for osteoarthritis and other } \\
\text { degenerative joint diseases }\end{array}$ & 47.21 & 2.43 & 23.97 \\
\hline & Chronic disease-drug group for colitis and related diseases & 22.46 & 2.21 & 21.76 \\
\hline & Chronic disease-drug group for osteoporosis & 20.89 & 1.99 & 19.58 \\
\hline & $\begin{array}{c}\text { Chronic disease-drug group for esophagus, stomach, and duodenum } \\
\text { diseases }\end{array}$ & 13.80 & 1.90 & 18.70 \\
\hline & Chronic disease-drug group for thyroid diseases & 8.76 & 1.58 & 15.60 \\
\hline & Chronic disease-drug group for autoimmune diseases & 3.12 & 1.43 & 14.13 \\
\hline & Chronic disease group for deafness and hearing loss & 13.77 & 1.40 & 13.77 \\
\hline \multirow{15}{*}{$\begin{array}{c}5 \\
\text { Cardio-cerebrovascular } \\
\text { and Renal } \\
(n=80,855: 8.82 \%)\end{array}$} & Chronic disease-drug group for peripheral vascular disease & 12.02 & 4.71 & 41.57 \\
\hline & Chronic disease-drug group for ischemic heart disease & 29.85 & 3.89 & 34.32 \\
\hline & Chronic disease-drug group for cerebrovascular diseases & 19.34 & 2.99 & 26.37 \\
\hline & Chronic disease-drug group for heart failure & 21.10 & 2.83 & 24.94 \\
\hline & Chronic disease group for bradycardias and conduction diseases & 7.04 & 2.53 & 22.33 \\
\hline & Chronic disease-drug group for atrial fibrillation & 15.98 & 2.39 & 21.06 \\
\hline & $\begin{array}{l}\begin{array}{l}\text { Chronic disease-drug group for other psychiatric and behavioral } \\
\text { diseases }\end{array} \\
\end{array}$ & 4.63 & 2.30 & 20.33 \\
\hline & Chronic disease-drug group for chronic kidney diseases & 21.85 & 2.07 & 18.27 \\
\hline & Chronic disease-drug group for COPD, emphysema, chronic bronchitis & 15.85 & 1.98 & 17.45 \\
\hline & Chronic disease-drug group for colitis and related diseases & 19.64 & 1.93 & 17.04 \\
\hline & Chronic disease-drug group for anemia & 11.32 & 1.93 & 17.00 \\
\hline & $\begin{array}{c}\text { Chronic disease-drug group for neurotic, stress-related, and } \\
\text { somatoform diseases }\end{array}$ & 18.28 & 1.79 & 15.79 \\
\hline & Chronic disease-drug group for prostate diseases & 17.96 & 1.78 & 15.67 \\
\hline & Chronic disease-drug group for depression and mood diseases & 21.75 & 1.75 & 15.45 \\
\hline & Chronic disease-drug group for sleep disorders & 9.50 & 1.67 & 14.69 \\
\hline
\end{tabular}


Table 1. Cont.

\begin{tabular}{|c|c|c|c|c|}
\hline Pattern & Disease or Disease-Medication Category & $\mathbf{O}$ & O/E Ratio & EX \\
\hline \multirow{15}{*}{$\begin{array}{c}6 \\
\text { Cardiovascular, Renal, } \\
\text { Inflammatory, and } \\
\text { Respiratory } \\
(n=69,720: 7.61 \%)\end{array}$} & Chronic disease-drug group for atrial fibrillation & 40.07 & 5.99 & 45.54 \\
\hline & Chronic disease-drug group for heart failure & 42.57 & 5.70 & 43.38 \\
\hline & Chronic disease group for bradycardias and conduction diseases & 11.50 & 4.14 & 31.48 \\
\hline & Chronic disease-drug group for inflammatory arthropathies & 11.16 & 3.34 & 25.41 \\
\hline & Chronic disease-drug group for autoimmune diseases & 7.07 & 3.25 & 24.69 \\
\hline & Chronic disease-drug group for anemia & 17.61 & 3.00 & 22.81 \\
\hline & Chronic disease-drug group for chronic kidney diseases & 31.24 & 2.96 & 22.52 \\
\hline & $\begin{array}{l}\text { Chronic disease-drug group for COPD, emphysema, chronic } \\
\text { bronchitis }\end{array}$ & 20.53 & 2.56 & 19.49 \\
\hline & Chronic disease-drug group for ischemic heart disease & 17.01 & 2.22 & 16.86 \\
\hline & Chronic disease-drug group for peripheral vascular disease & 5.36 & 2.10 & 15.97 \\
\hline & $\begin{array}{l}\text { Chronic disease group for chronic pancreas, biliary tract, and } \\
\text { gallbladder diseases }\end{array}$ & 4.88 & 1.64 & 12.45 \\
\hline & Chronic disease-drug group for cerebrovascular diseases & 10.29 & 1.59 & 12.10 \\
\hline & Chronic disease-drug group for colitis and related diseases & 15.91 & 1.56 & 11.90 \\
\hline & Chronic disease-drug group for prostate diseases & 14.98 & 1.48 & 11.27 \\
\hline & Chronic disease-drug group for hypertension & 83.43 & 1.47 & 11.16 \\
\hline \multirow{15}{*}{$\begin{array}{c}7 \\
\text { Multisystem } \\
(n=49,592: 5.41 \%)\end{array}$} & Chronic disease group for other digestive diseases & 23.29 & 9.70 & 52.46 \\
\hline & Chronic disease-drug group for dementia & 21.63 & 6.48 & 35.07 \\
\hline & $\begin{array}{l}\text { Chronic disease group for chronic pancreas, biliary tract, and } \\
\text { gallbladder diseases }\end{array}$ & 16.95 & 5.69 & 30.77 \\
\hline & Chronic disease-drug group for autoimmune diseases & 10.95 & 5.03 & 27.19 \\
\hline & Chronic disease-drug group for inflammatory arthropathies & 14.80 & 4.43 & 23.97 \\
\hline & Chronic disease-drug group for anemia & 19.82 & 3.37 & 18.25 \\
\hline & Chronic disease-drug group for atrial fibrillation & 14.80 & 2.21 & 11.96 \\
\hline & Chronic disease-drug group for heart failure & 16.37 & 2.19 & 11.87 \\
\hline & Chronic disease-drug group for colitis and related diseases & 19.34 & 1.90 & 10.29 \\
\hline & Chronic disease-drug group for chronic kidney diseases & 19.73 & 1.87 & 10.12 \\
\hline & Chronic disease group for bradycardias and conduction diseases & 4.49 & 1.61 & 8.73 \\
\hline & Chronic disease-drug group for COPD, emphysema, chronic bronchitis & 12.50 & 1.56 & 8.44 \\
\hline & Chronic disease-drug group for cerebrovascular diseases & 10.06 & 1.55 & 8.41 \\
\hline & $\begin{array}{l}\begin{array}{l}\text { Chronic disease-drug group for esophagus, stomach, and duodenum } \\
\text { diseases }\end{array} \\
\text {. }\end{array}$ & 9.95 & 1.37 & 7.41 \\
\hline & $\begin{array}{c}\text { Chronic disease-drug group for osteoarthritis and other degenerative } \\
\text { joint diseases }\end{array}$ & 25.47 & 1.31 & 7.10 \\
\hline
\end{tabular}

Categories highlighted in gray are chronic disease categories; those in white are chronic disease-drug categories. Categories in bold reach the $\mathrm{O} / \mathrm{E}$ ratio threshold of two. Abbreviations: O: disease prevalence in the cluster; $\mathrm{O} / \mathrm{E}$ ratio: observed/expected ratio; Ex: exclusivity; COPD: chronic obstructive pulmonary disease.

Cluster 1 (non-specific) included a substantial number of individuals that do not present any overrepresented chronic disease or chronic disease-drug category $(\mathrm{O} / \mathrm{E}$ ratios are below two and exclusivity values are below $30 \%$ ). Cluster 1 was also the cluster with the lowest average age (74.20 years, SD 7.47) and the lowest percentage of individuals with multimorbidity $(81.74 \%)$ and polypharmacy $(15.38 \%)$. 
Diabetes (Cluster 2): The only category that surpassed the O/E ratio threshold was chronic disease-drug group for "diabetes" (O/E ratio 2.15), with exclusivity of $41.93 \%$.

Neurological and musculoskeletal, female dominant (Cluster 3): 69.05\% of the individuals in this cluster were female, with exclusivity for the chronic disease-drug groups for "peripheral neuropathy", "dorsopathies", and "other musculoskeletal and joint diseases" all surpassing $30 \%$. Similar to Cluster 3 is behavioral, neurological, and musculoskeletal, female dominant (Cluster 4$)$, which also has a high proportion of females $(75.08 \%)$ and contains many of the chronic disease-drug groups from the neurological and musculoskeletal categories. However, the differentiating factor is the emphasis on behavioral chronic disease-drug groups, with several groups pertaining to this category as well.

Cardio-cerebrovascular and renal (Cluster 5): The vast majority (six out of eight) of the significant groups in this cluster are cardiovascular related, with exclusivity of chronic disease-drug groups for "peripheral vascular disease" and "ischemic heart disease" both exceeding 30\%. This cluster contained the highest proportion of polypharmacy (83.65\%).

Cardiovascular, renal, inflammatory, and respiratory (Cluster 6): Cardiovascular categories occupy the top three spots, with chronic disease-drug categories for "atrial fibrillation" (O/E ratio 5.99) and "heart failure" (O/E ratio 5.70), and chronic disease category "bradycardias and conduction disorders" (O/E ratio 4.14), all exceeding an exclusivity of $30 \%$. This cluster contained the highest proportions for individuals diagnosed with 10 or more chronic diseases $(30.82 \%)$, individuals prescribed 10 or more chronic drugs $(27.71 \%)$, and individuals with 10 or more primary care visits $(75.38 \%)$. Polypharmacy was nearly that of Cluster $5(83.54 \%)$.

The multisystem pattern identified in Cluster 7 represents the smallest group of individuals from the study population (5.41\%) and contains several overrepresented diseases corresponding to multiple systems, in which individuals with digestive disease dominate the cluster.

Socioeconomic status (measured by MEDEA index) between categories appears to remain relatively stable in Cluster 2 to Cluster 7 , with most deprived fluctuating between $13.63-15.79 \%$ and least deprived between $14.90-16.57 \%$. Those in rural health settings fluctuate between $19.34-23.83 \%$ in Cluster 2 to Cluster 7.

\section{Discussion}

\subsection{Key Results}

In this article, patterns for multimorbidity and polypharmacy were analyzed in a joint manner by means of creating a variable relating each drug to one or more diseases for which they are indicated. Such patterns were obtained via specified criteria that allowed for the identification of multimorbid individuals that also qualified as polymedicated (those who were invoiced more than five distinct drugs in one year). This study ultimately identified distinct patterns with singular characteristics, with some more profound in women than in men. This is a key point in order to carry out a stricter follow up of the individuals who have a higher risk of presenting secondary effects caused by drugs or drug interaction.

Cluster 1 (non-specific) did not overrepresent any disease and Cluster 7 (multisystemic) overrepresented diseases from many systems are less specific than Clusters 2 to 6. These cluster types have been identified in other studies $[35,36]$. In our study, we were able to identify overrepresented diseases that do not have any prescribed drug in primary healthcare, such as neoplastic disease, deafness and hearing loss, and bradycardias and conduction diseases. These data suggest that diseases and drugs should be considered in combination to more efficiently identify multimorbidity patterns [37].

It was observed that the chronic disease-drug categories "hypertension" and "dyslipidemia" are distributed throughout the seven obtained clusters. Individuals with these common pathologies are therefore not grouped together in any one specific cluster; rather, they are spread throughout all seven. The fuzzy c-means method is a technique that classifies individuals based on cluster probability membership, and, given that there were 
many individuals with these chronic diseases and associated drugs in the study, the results are homogenously distributed throughout the study population [37].

The patterns from Cluster 2 to Cluster 6 group individuals who share similar chronic disease-drug categories. Cluster 2 is classified as diabetes because $41.93 \%$ of individuals included in the cluster are diabetic. Although not reaching the O/E threshold of two, associations are still observed between diabetes and obesity, cataracts, and neoplasms, all diseases that are frequently presented in diabetic individuals [38-40].

Cluster 3 (neurological and musculoskeletal) and Cluster 4 (behavioral, neurological, and musculoskeletal) include patterns predominantly in women. The clustering model identified these two groups of individuals that present similar health problems with singular characteristics. The patterns within behavioral, neurological, and musculoskeletal show an association with autoimmune diseases that are also more frequent in women [41].

Cluster 5 (cardio-cerebrovascular and renal) and Cluster 6 (cardiovascular, renal, inflammatory, and respiratory) include chronic disease-drug patterns that primarily treat cardiac, cardiovascular, cerebrovascular, and renal pathologies. This association, which has been observed in a previous study that indicated a pattern of increased mortality [16], concerns closely related pathologies that also share risk factors and even treatments. This study allows for the grouping of individuals with similar chronic disease and chronic disease-drug categories into two differentiated and specific clusters, given that Cluster 6 (cardiovascular, renal, inflammatory, and respiratory) includes a chronic disease-drug category for inflammatory pathologies as well as a chronic disease-drug group for respiratory diseases. Chronic inflammation as a mechanism in atherosclerosis carries a higher risk for cardiovascular and cerebrovascular events [42]. Autoimmune diseases and arthrosis have also been linked to an increase in cardiovascular disease, although this could be due to adverse effects of the treatments for these diseases, such as corticoids [43,44].

A small group of individuals who presented polypharmacy did not satisfy the condition for multimorbidity. This could be due to the individuals having received multiple treatments during the study period without them coinciding. On the other hand, there is also the possibility that some pathologies could be treated with five or more drugs simultaneously for certain patients, with neuropathy being a prime example.

The inclusion of the same study variable for chronic diseases and drugs indicated for their respective diseases' treatment is an advantage that allows for a better identification of the individuals and, thereby, allows to better orient the clinical management of these groups of individuals.

The methodology used for mapping drugs and chronic diseases permitted the identification of a new chronic diseases-drug category. This new variable applied to fuzzy clustering methods is less susceptible to outliers in the data, choice of distance measure, and the inclusion of inappropriate or irrelevant variables [35,45,46].

This mapping process between chronic diseases and drugs, together with the application of the fuzzy method, will be very useful for multimorbidity studies where drugs are used as a proxy variable.

Soft clustering methods offer a new methodological approach towards understanding the relationships between specific diseases or drugs in individuals. This is an essential step in improving the care of patients and the quality of health systems. Analyzing multimorbidity patterns based on drugs permits the identification of patient subgroups with different clinical approaches and attention. Our analysis focuses on groups of patients with specific diseases and drugs as opposed to other studies centered in diseases.

This methodology can be applied in a large variety of studies using electronic health records to study polypharmacy and multimorbidity.

\subsection{Comparison to the Literature}

Studies performed with clustering methods concerning multimorbidity and polypharmacy are novel but becoming more frequent [47]; however, these studies generally approach multimorbidity with a polypharmacy perspective or vice versa. To the authors' knowledge, 
this study is the first in conveying a combined approach to multimorbidity and polypharmacy by combining both topics into one inclusive variable to determine joint outcomes. Although, as previously mentioned, some of the patterns obtained (neurological and musculoskeletal, female dominant; behavioral, neurological, and musculoskeletal, female dominant; and cardio-cerebrovascular and renal) coincide with the literature $[17,37,48]$.

\subsection{Strengths and Limitations}

The sample size, with nearly one million individuals, is a clear advantage of the study. Considering individuals as the primary variable for analysis rather than diseases [34], the study employs a large, high-quality database composed of primary health care records representative of the Catalan population aged $\geq 65$ years [24], an age group that is more susceptible to present health problems related to drugs. The inclusion of all drugs that are indicated for different diseases with a minimum number of packages facilitates the identification of those individuals who should be more thoroughly monitored. Regarding the method, soft clustering offers a methodologic focus in understanding the relations between specific diseases and individuals. The analysis of multimorbidity and polypharmacy patterns can identify subgroups of patients with different associated diseases and drugs. The extensive mapping process of drug categories to their respective SNAC-K chronic disease categories provides a further level of detail than most other clustering techniques within the literature. This can ultimately serve as a framework for future studies that wish to map diseases and drugs under certain conditions to determine combined patterns.

Some limitations of this study should be considered. Individuals who met initial selection criteria but sought care outside of $\mathrm{CHI}$ governance were ineligible, possibly introducing selection bias for individuals who chose to seek care in a private healthcare facility. However, this is a small group of the population, and the results of this study can be applied to the general population. Drugs were recorded via invoices, and hospital drugs were not included, which could have influenced the calculation for polypharmacy. Concerning the clusters, the results obtained in this study are similar to those obtained in other studies without prior mapping; nevertheless, we consider that this methodology more precisely determines which pathologies and drugs are overrepresented in each cluster, thus more adequately defining patient profiles. Finally, while the fuzzy c-means clustering technique used in this study is an unsupervised, exploratory method, the authors believe that, combined with a vigorous internal validation system, this technique produces robust results and minimizes potential pitfalls.

\section{Conclusions}

This study utilized a mapping process combined with a soft clustering technique to determine combined patterns of multimorbidity and polypharmacy in the elderly Catalan population in 2012, identifying overrepresentation in 6 of the 7 clusters with chronic disease and chronic disease-drug categories. Cluster 2 to Cluster 6 provided recognizable patterns, predominantly in diabetes; neurological and musculoskeletal, female dominant and behavioral, neurological, and musculoskeletal, female dominant; and cardio-cerebrovascular and renal and cardiovascular, renal, inflammatory, and respiratory. These patterns further highlight the differences between sexes, specifically within neurological and musculoskeletal, female dominant and behavioral, neurological, and musculoskeletal, female dominant.

The combined patterns of multimorbidity and polypharmacy identified in this study will contribute key information to the evaluation of multimorbid and polymedicated individuals, facilitating the identification of these subgroups of individuals that require specific attention. The obtained results could be applied to clinical practice guidelines differentiating distinct population groups, such as multimorbid individuals with and without associated diseases and/or polypharmacy. Due to the relationship between multimorbidity and polypharmacy over long periods of time, this analysis could serve as the base to deepen this relationship in further longitudinal studies. The patterns obtained in this research will 
allow for an in-depth study of the prescription of multiple medications in elderly people in relation to medication-related problems.

Supplementary Materials: The following are available online at https://www.mdpi.com/article/ 10.3390/ijerph18179216/s1, Figure S1: validation indices, Table S1: mapping of SNAC-K chronic disease categories and their associated ATC drugs categories.

Author Contributions: Conceptualization, A.R.-L. and C.V.; methodology, G.S., N.V., A.R.-L., A.T.-M., and C.V.; software, G.S. and A.R.-L.; validation, N.V. and A.T.-M.; formal analysis, G.S. and A.R.-L.; investigation, G.S., N.V., A.R.-L., A.T.-M., and C.V.; resources, A.R.-L. and C.V.; data curation, G.S. and A.R.-L.; writing—original draft preparation, G.S., N.V., and C.V.; writing-review and editing, G.S., N.V., A.R.-L., A.T.-M., M.M., and C.V.; visualization, G.S. and A.R.-L.; supervision, A.R.-L. and C.V.; project administration, C.V.; funding acquisition, C.V. All authors have read and agreed to the published version of the manuscript.

Funding: This work was supported by a research grant from the Instituto de Salud Carlos III, under the auspices of the Ministry of Science, Innovation and Universities, awarded in the 2016 call under the Health Strategy Action 2013-2016, within the National Research Program oriented to Societal Challenges, within the Technical, Scientific and Innovation Research National Plan 2013-2016 (Grant Number PI16/00639), co-funded with the EU European Regional Development Fund and the Department of Health of the Catalan Government, in the 2017 call that awarded subsidies for the Strategic Plan for Research in Health (Pla Estratègic de Recerca i Innovació en Salut, PERIS) 2016-2020, modality research oriented to primary care (Grant Number SLT002/16/00058) and by the Catalan Government (Grant Number AGAUR 2017 SGR 578). This project has been partially funded by the Carlos III Health Institute (Ministry of Economy and Competitiveness, Spain) through the Network for Prevention and Health Promotion in Primary Care (redIAPP, RD16/0007/0001) and by European Union European Regional Development Fund (ERDF) funds (European Regional Development Fund).

Institutional Review Board Statement: The study was conducted according to the guidelines of the Declaration of Helsinki, and approved by the Clinical Research Ethics Committee, Fundació Institut Universitari per a la Recerca a l'Atenció Primària de Salut Jordi Gol i Gurina (IDIAPJGol) (Protocol No: P17/080). All data were anonymized in agreement with national and international law.

Informed Consent Statement: Not applicable.

Data Availability Statement: The datasets are not available, since researchers signed an agreement with the Information System for the Development of Research in Primary Care (SIDIAP) concerning confidentiality and security of the dataset, which forbids providing data to third parties. The SIDIAP is subject to periodic audits.

Acknowledgments: We thank the Catalan Institute of Health and the SIDIAP, which provided the database for the study.

Conflicts of Interest: The authors declare no conflict of interest.

\section{Appendix A}

Table A1. Prevalence of the 60 chronic diseases included in the study in individuals aged 65-99 years $(n=916,619$, Catalonia, 2012). In the last column, list of diseases included by prevalence cut off of $2 \%$.

\begin{tabular}{|c|c|c|c|c|}
\hline Rank & Chronic Conditions & Frequency & Percentage (\%) & Cut Off of $2 \%$ \\
\hline 1 & Hypertension & 650,899 & 71.0 & \\
\hline 2 & Dyslipidemia & 466,585 & 50.9 & \\
\hline 3 & Osteoarthritis and other degenerative joint diseases & 300,803 & 32.8 & \\
\hline 4 & Obesity & 262,888 & 28.7 & \\
\hline 5 & Diabetes & 230,460 & 25.1 & \\
\hline 6 & Anemia & 167,577 & 18.3 & \\
\hline 7 & Cataract and other lens diseases & 156,622 & 17.1 & \\
\hline
\end{tabular}


Table A1. Cont.

\begin{tabular}{|c|c|c|c|c|}
\hline Rank & Chronic Conditions & Frequency & Percentage (\%) & Cut Off of $2 \%$ \\
\hline 8 & Chronic kidney diseases & 153,756 & 16.8 & \\
\hline 9 & Prostate diseases & 153,635 & 16.8 & \\
\hline 10 & Osteoporosis & 151,847 & 16.6 & \\
\hline 11 & Depression and mood diseases & 148,751 & 16.2 & \\
\hline 12 & Solid neoplasms & 137,045 & 15.0 & \\
\hline 13 & Colitis and related diseases & 131,512 & 14.4 & \\
\hline 14 & Venous and lymphatic diseases & 126,997 & 13.9 & \\
\hline 15 & Other musculoskeletal and joint diseases & 124,765 & 13.6 & \\
\hline 16 & Dorsopathies & 124,603 & 13.6 & \\
\hline 17 & Neurotic, stress-related and somatoform diseases & 123,395 & 13.5 & \\
\hline 18 & COPD, emphysema, chronic bronchitis & 109,603 & 12.0 & \\
\hline 19 & Ischemic heart disease & 95,434 & 10.4 & \\
\hline 20 & Deafness, hearing impairment & 90,261 & 9.9 & \\
\hline 21 & Sleep disorders & 88,739 & 9.7 & \\
\hline 22 & Thyroid diseases & 88,445 & 9.7 & \\
\hline 23 & Other genitourinary diseases & 85,468 & 9.3 & \\
\hline 24 & Cerebrovascular disease & 80,264 & 8.8 & \\
\hline 25 & Atrial fibrillation & 80,247 & 8.8 & \\
\hline 26 & Esophagus, stomach and duodenum diseases & 80,043 & 8.7 & \\
\hline 27 & Heart failure & 74,077 & 8.1 & \\
\hline 28 & Other eye diseases & 68,939 & 7.5 & \\
\hline 29 & Glaucoma & 66,162 & 7.2 & \\
\hline 30 & Inflammatory arthropathies & 62,450 & 6.8 & \\
\hline 31 & Dementia & 59,213 & 6.5 & \\
\hline 32 & Cardiac valve diseases & 52,100 & 5.7 & \\
\hline 33 & Peripheral neuropathy & 49,127 & 5.4 & \\
\hline 34 & Other psychiatric and behavioral diseases & 46,841 & 5.1 & \\
\hline 35 & Asthma & 43,663 & 4.8 & \\
\hline 36 & Allergy & 40,394 & 4.4 & \\
\hline 37 & Autoimmune diseases & 39,350 & 4.3 & \\
\hline 38 & Ear, nose, throat diseases & 38,752 & 4.2 & \\
\hline 39 & Peripheral vascular disease & 30,674 & 3.4 & \\
\hline 40 & Other neurological diseases & 28,541 & 3.1 & \\
\hline 41 & Chronic pancreas, biliary tract and gallbladder diseases & 27,321 & 3.0 & \\
\hline 42 & Migraine and facial pain syndromes & 25,999 & 2.8 & \\
\hline 43 & Bradycardias and conduction diseases & 25,476 & 2.8 & \\
\hline 44 & Chronic liver diseases & 22,633 & 2.5 & \\
\hline 45 & Other digestive diseases & 22,022 & 2.4 & \\
\hline 46 & Parkinson and parkinsonism & 20,833 & 2.3 & \\
\hline 47 & Other metabolic diseases & 18,997 & 2.1 & \\
\hline
\end{tabular}


Table A1. Cont.

\begin{tabular}{|c|c|c|c|c|}
\hline Rank & Chronic Conditions & Frequency & Percentage $(\%)$ & Cut Off of $2 \%$ \\
\hline 48 & Other cardiovascular diseases & 16,833 & 1.8 & \\
\hline 49 & Other skin diseases & 15,363 & 1.7 & \\
\hline 50 & Chronic ulcer of the skin & 13,869 & 1.5 & \\
\hline 51 & Blood and blood forming organ diseases & 13,575 & 1.5 & \\
\hline 52 & Other respiratory diseases & 9974 & 1.1 & \\
\hline 53 & Epilepsy & 8981 & 1.0 & \\
\hline 54 & Hematological neoplasms & 8174 & 0.9 & \\
\hline 55 & Chronic infectious diseases & 6647 & 0.7 & \\
\hline 56 & Inflammatory bowel diseases & 5549 & 0.6 & \\
\hline 57 & Schizophrenia and delusional diseases & 4792 & 0.5 & \\
\hline 58 & Blindness, visual impairment & 4772 & 0.5 & \\
\hline 59 & Multiple sclerosis & 576 & 0.1 & \\
\hline 60 & Chromosomal abnormalities & 77 & 0.0 & \\
\hline
\end{tabular}

Abbreviations: COPD: chronic obstructive pulmonary disease. The black shading in the lower part of the table IS necessary, as it indicates a cut off of $2 \%$, as defined in the first line.

Table A2. Prevalence of the 89 medication categories diseases included in the study in individuals aged 65-99 years ( $n=916,619$, Catalonia, 2012).

\begin{tabular}{|c|c|c|c|c|}
\hline Rank & ATC-5 Code & Medication Categories & Frequency & Percentage $(\%)$ \\
\hline 1 & $\mathrm{~A} 02 \mathrm{BC}$ & Proton pump inhibitors & 405,942 & 44.29 \\
\hline 2 & C10AA & HMG CoA reductase inhibitors & 349,676 & 38.15 \\
\hline 3 & N02BE & Anilides & 260,018 & 28.37 \\
\hline 4 & B01AC & Platelet aggregation inhibitors excl. heparin & 234,306 & 25.56 \\
\hline 5 & N05BA & Benzodiazepine derivatives & 191,870 & 20.93 \\
\hline 6 & C09AA & ACE inhibitors, plain & 182,906 & 19.95 \\
\hline 7 & A10BA & Biguanides & 119,955 & 13.09 \\
\hline 8 & C08CA & Dihydropyridine derivatives & 116,713 & 12.73 \\
\hline 9 & N06AB & Selective serotonin reuptake inhibitors & 116,497 & 12.71 \\
\hline 10 & $\mathrm{C} 07 \mathrm{AB}$ & Beta blocking agents, selective & 102,442 & 11.18 \\
\hline 11 & C03CA & Sulfonamides, plain & 101,933 & 11.12 \\
\hline 12 & C09CA & Angiotensin II antagonists, plain & 99,742 & 10.88 \\
\hline 13 & A12AX & Calcium, combinations with vitamin D and/or other drugs & 93,581 & 10.21 \\
\hline 14 & C03AA & Thiazides, plain & 86,414 & 9.43 \\
\hline 15 & C09DA & Angiotensin II antagonists and diuretics & 80,115 & 8.74 \\
\hline 16 & M01AE & Propionic acid derivatives & 79,393 & 8.66 \\
\hline 17 & C09BA & ACE inhibitors and diuretics & 74,494 & 8.13 \\
\hline 18 & G04CA & Alpha-adrenoreceptor antagonists & 71,028 & 7.75 \\
\hline 19 & B01AA & Vitamin $\mathrm{K}$ antagonists & 62,331 & 6.80 \\
\hline 20 & M05BA & Bisphosphonates & 62,313 & 6.80 \\
\hline 21 & R03BB & Anticholinergics & 53,159 & 5.80 \\
\hline 22 & N05CD & Benzodiazepine derivatives & 52,859 & 5.77 \\
\hline 23 & A10BB & Sulfonylureas & 50,812 & 5.54 \\
\hline 24 & H03AA & Thyroid hormones & 50,699 & 5.53 \\
\hline 25 & R03AK & $\begin{array}{c}\text { Adrenergics in combination with corticosteroids or other } \\
\text { drugs, excl. anticholinergics }\end{array}$ & 50,644 & 5.53 \\
\hline
\end{tabular}


Table A2. Cont.

\begin{tabular}{|c|c|c|c|c|}
\hline Rank & ATC-5 Code & Medication Categories & Frequency & Percentage $(\%)$ \\
\hline 26 & N02AX & Other opioids & 48,388 & 5.28 \\
\hline 27 & M04AA & Preparations inhibiting uric acid production & 47,629 & 5.20 \\
\hline 28 & N06AX & Other antidepressants & 45,357 & 4.95 \\
\hline 29 & R03AC & Selective beta-2-adrenoreceptor agonists & 43,972 & 4.80 \\
\hline 30 & S01ED & Beta blocking agents & 42,513 & 4.64 \\
\hline 31 & C01DA & Organic nitrates & 41,674 & 4.55 \\
\hline 32 & S01EE & Prostaglandin analogues & 40,643 & 4.43 \\
\hline 33 & N03AX & Other antiepileptics & 37,873 & 4.13 \\
\hline 34 & B03AA & Iron bivalent, oral preparations & 35,13 & 3.83 \\
\hline 35 & M01AX & $\begin{array}{l}\text { Other anti-inflammatory and antirheumatic agents, } \\
\text { non-steroids }\end{array}$ & 34,490 & 3.76 \\
\hline 36 & M01AB & Acetic acid derivatives and related substances & 30,848 & 3.37 \\
\hline 37 & N02BB & Pyrazolones & 30,600 & 3.34 \\
\hline 38 & C02CA & Alpha-adrenoreceptor antagonists & 26,333 & 2.87 \\
\hline 39 & N07CA & Antivertigo preparations & 25,290 & 2.76 \\
\hline 40 & C01EB & Other cardiac preparations & 24,272 & 2.65 \\
\hline 41 & G04BD & Drugs for urinary frequency and incontinence & 23,646 & 2.58 \\
\hline 42 & D01AC & Imidazole and triazole derivatives & 23,459 & 2.56 \\
\hline 43 & A03FA & Propulsives & 22,461 & 2.45 \\
\hline 44 & A10AE & Insulins and analogues for injection, long-acting & 21,678 & 2.36 \\
\hline 45 & $\mathrm{H} 02 \mathrm{AB}$ & Glucocorticoids & 21,493 & 2.34 \\
\hline 46 & C01AA & Digitalis glycosides & 21,190 & 2.31 \\
\hline 47 & D07AC & Corticosteroids, potent (Group III) & 20,599 & 2.25 \\
\hline 48 & G04CB & Testosterone-5-alpha reductase inhibitors & 19,379 & 2.11 \\
\hline 49 & N06DA & Anticholinesterases & 19,366 & 2.11 \\
\hline 50 & C08DB & Benzothiazepine derivatives & 19,211 & 2.10 \\
\hline 51 & R03BA & Glucocorticoids & 19,143 & 2.09 \\
\hline 52 & R06AX & Other antihistamines for systemic use & 18,609 & 2.03 \\
\hline 53 & C07AG & Alpha and beta blocking agents & 18,198 & 1.99 \\
\hline 54 & A02BA & H2-receptor antagonists & 18,158 & 1.98 \\
\hline 55 & C03BA & Sulfonamides, plain & 17,998 & 1.96 \\
\hline 56 & $\mathrm{C} 10 \mathrm{AB}$ & Fibrates & 17,874 & 1.95 \\
\hline 57 & N05CF & Benzodiazepine related drugs & 17,914 & 1.95 \\
\hline 58 & G03CA & Natural and semisynthetic estrogens, plain & 16,513 & 1.80 \\
\hline 59 & C03DA & Aldosterone antagonists & 16,367 & 1.79 \\
\hline 60 & N06DX & Other anti-dementia drugs & 16,292 & 1.78 \\
\hline 61 & A10BD & Combinations of oral blood glucose lowering drugs & 15,397 & 1.68 \\
\hline 62 & N06AA & Non-selective monoamine reuptake inhibitors & 15,364 & 1.68 \\
\hline 63 & N05AH & Diazepines, oxazepines, thiazepines and oxepines & 14,249 & 1.55 \\
\hline 64 & R01AD & Corticosteroids & 13,880 & 1.51 \\
\hline 65 & G04CX & Other drugs used in benign prostatic hypertrophy & 13,684 & 1.49 \\
\hline
\end{tabular}


Table A2. Cont.

\begin{tabular}{|c|c|c|c|c|}
\hline Rank & ATC-5 Code & Medication Categories & Frequency & Percentage $(\%)$ \\
\hline 66 & J01MA & Fluoroquinolones & 13,610 & 1.48 \\
\hline 67 & C03EA & Low-ceiling diuretics and potassium-sparing agents & 13,179 & 1.44 \\
\hline 68 & A10BX & Other blood glucose lowering drugs, excl. insulins & 12,933 & 1.41 \\
\hline 69 & A12AA & Calcium & 12,809 & 1.40 \\
\hline 70 & C09DB & Angiotensin II antagonists and calcium channel blockers & 12,698 & 1.39 \\
\hline 71 & A12BA & Potassium & 12,625 & 1.38 \\
\hline 72 & J01CR & Combinations of penicillins, incl. beta-lactamase inhibitors & 12,658 & 1.38 \\
\hline 73 & C04AD & Purine derivatives & 12,589 & 1.37 \\
\hline 74 & C10AX & Other lipid modifying agents & 12,579 & 1.37 \\
\hline 75 & M01AH & Coxibs & 12,537 & 1.37 \\
\hline 76 & N04BA & Dopa and dopa derivatives & 12,280 & 1.34 \\
\hline 77 & D01AE & Other antifungals for topical use & 11,514 & 1.26 \\
\hline 78 & A11CC & Vitamin D and analogues & 11,262 & 1.23 \\
\hline 79 & A10AD & $\begin{array}{l}\text { Insulins and analogues for injection, intermediate- or } \\
\text { long-acting combined with fast-acting }\end{array}$ & 11,056 & 1.21 \\
\hline 80 & A10AC & Insulins and analogues for injection, intermediate-acting & 10,925 & 1.19 \\
\hline 81 & N02AB & Phenylpiperidine derivatives & 10,802 & 1.18 \\
\hline 82 & B03BA & Vitamin B12 (cyanocobalamin and analogues) & 10,613 & 1.16 \\
\hline 83 & C01BD & Antiarrhythmics, class III & 10,511 & 1.15 \\
\hline 84 & N05AX & Other antipsychotics & 10,404 & 1.14 \\
\hline 85 & C07AA & Beta blocking agents, non-selective & 10,231 & 1.12 \\
\hline 86 & S01EC & Carbonic anhydrase inhibitors & 9737 & 1.06 \\
\hline 87 & $\mathrm{~B} 03 \mathrm{AB}$ & Iron trivalent, oral preparations & 9504 & 1.04 \\
\hline 88 & N03AE & Benzodiazepine derivatives & 9211 & 1.00 \\
\hline 89 & M05BX & Other drugs affecting bone structure and mineralization & 7652 & 0.83 \\
\hline
\end{tabular}

Abbreviations: HMGCoA-reductase: 3-Hidroxi-3-metil-glutaril-CoA reductase; ACE inhibitors: angiotensin converting enzyme inhibitors.

Table A3. Mapping of SNAC-K chronic disease categories and their associated ATC drugs categories (first two categories).

\section{ALLERGY}

ICD-10 codes and labels included in chronic disease category

\begin{tabular}{cccc}
\hline J301 & Allergic rhinitis due to pollen & R01AD & Corticosteroids (nasal use) \\
\hline J302 & Other seasonal allergic rhinitis & R03AC & Selective beta-2-adrenoreceptor agonists \\
\hline J303 & Other allergic rhinitis & R03AK & $\begin{array}{c}\text { Adrenergics in combination with corticosteroids } \\
\text { or other drugs, excl. anticholinergics }\end{array}$ \\
\hline J304 & Allergic rhinitis, unspecified & R03BA & Glucocorticoids (inhalation) \\
\hline J450 & Predominantly allergic asthma & R03BB & Anticholinergics \\
\hline K522 & Allergic and dietetic gastroenteritis and colitis & R06AX & Other antihistamines for systemic use \\
\hline L20 & Atopic dermatitis & D07AC & Corticosteroids, potent (Group III) (topical use) \\
\hline L23 & Allergic contact dermatitis & & \\
\hline L500 & Allergic urticaria & & \\
\hline Z516 & Desensitization to allergens & &
\end{tabular}

ATC-5 codes and labels for drugs associated to chronic disease category. Includes none or any of the following: 
Table A3. Cont.

\begin{tabular}{|c|c|c|c|}
\hline \multicolumn{4}{|c|}{ ANEMIA } \\
\hline \multicolumn{2}{|c|}{ ICD-10 codes and labels included in chronic disease category } & \multicolumn{2}{|c|}{$\begin{array}{l}\text { ATC-5 codes and labels for drugs associated to chronic disease } \\
\text { category. Includes none or any of the following: }\end{array}$} \\
\hline D50 & Iron deficiency anaemia & B03AA & Iron bivalent, oral preparations \\
\hline D51 & Vitamin B12 deficiency anaemia & B03AB & Iron trivalent, oral preparations \\
\hline D52 & Folate deficiency anaemia & B03BA & Vitamin B12 (cyanocobalamin and analogues) \\
\hline D53 & Other nutritional anaemias & $\mathrm{H} 02 \mathrm{AB}$ & Glucocorticoids (systemic use, plain) \\
\hline D55 & Anaemia due to enzyme disorders & & \\
\hline D56 & Thalassaemia & & \\
\hline D57 & Sickle-cell disorders & & \\
\hline D58 & Other hereditary haemolytic anaemias & & \\
\hline D59 & Acquired haemolytic anaemia & & \\
\hline D60 & $\begin{array}{l}\text { Acquired pure red cell aplasia } \\
\text { [erythroblastopenia] }\end{array}$ & & \\
\hline D61 & Other aplastic anaemias & & \\
\hline D63 & Anaemia in chronic diseases classified elsewhere & & \\
\hline D64 & Other anaemias & & \\
\hline
\end{tabular}

Only chronic diseases and their associated ATC drug categories resulting in chronic disease or chronic disease-drug categories $\geq 2 \%$ prevalence are included in this table. For the sake of brevity, only the first two mapped categories are shown. The complete mapping table can be found in Supplementary Materials Table S1. Remaining categories with $<2 \%$ prevalence can be sent to readers upon request. 
Table A4. Variables characterizing each cluster for chronic disease or chronic disease-drug category threshold of $2 \%(n=916,619)$.

\begin{tabular}{|c|c|c|c|c|c|c|c|c|}
\hline & 1. Non-Specific & 2. Diabetes & $\begin{array}{l}\text { 3. Neurological and } \\
\text { Musculoskeletal, } \\
\text { Female Dominant }\end{array}$ & $\begin{array}{l}\text { 4. Behavioral, } \\
\text { Neurological, and } \\
\text { Musculoskeletal, } \\
\text { Female Dominant }\end{array}$ & $\begin{array}{l}\text { 5. Cardio- } \\
\text { Cerebrovascular } \\
\text { and Renal }\end{array}$ & $\begin{array}{l}\text { 6. Cardiovascular, } \\
\text { Renal, } \\
\text { Inflammatory, and } \\
\text { Respiratory }\end{array}$ & 7. Multisystem & $\begin{array}{l}\text { Study Population } \\
\text { (All) }\end{array}$ \\
\hline Number of people, $n$ & 344,958 & 178,457 & 102,750 & 90,287 & 80,855 & 69,720 & 49,592 & 916,619 \\
\hline Multimorbidity, $n(\%)$ & $281,952(81.74)$ & $178,412(99.97)$ & $102,629(99.88)$ & 90,245 (99.95) & 80,819 (99.96) & $69,680(99.94)$ & 49,347 (99.51) & $853,084(93.07)$ \\
\hline Polypharmacy, $n(\%)$ & $53,070(15.38)$ & $105,323(59.02)$ & $69,503(67.64)$ & $68,276(75.62)$ & 67,635 (83.65) & $58,245(83.54)$ & 35,523 (71.63) & $457,575(49.92)$ \\
\hline Women, $n(\%)$ & $187,691(54.41)$ & $98,251(55.06)$ & 70,946 (69.05) & $67,785(75.08)$ & $39,649(49.04)$ & $35,130(50.39)$ & 29,679 (59.85) & $529,131(57.73)$ \\
\hline Age, mean (SD) & $74.28(7.47)$ & $74.61(6.86)$ & $75.82(7.07)$ & $75.43(7.06)$ & $77.06(7.34)$ & $78.47(7.30)$ & $78.27(7.52)$ & 75.41 (7.39) \\
\hline \multicolumn{9}{|l|}{ Age (categories), $n(\%)$} \\
\hline$[65,70)$ & $119,921(34.76)$ & $51,741(28.99)$ & $24,050(23.41)$ & $23,121(25.61)$ & 15,649 (19.35) & $9796(14.05)$ & 7901 (15.93) & $252,178(27.51)$ \\
\hline$[70,80)$ & $140,724(40.79)$ & $83,142(46.59)$ & 47,314 (46.05) & $41,082(45.5)$ & $34,708(42.93)$ & 28,197 (40.44) & 19,419 (39.16) & $394,586(43.05)$ \\
\hline$[80,90)$ & 71,317 (20.67) & $39,345(22.05)$ & $27,970(27.22)$ & $23,398(25.92)$ & $26,574(32.87)$ & $27,204(39.02)$ & $18,936(38.18)$ & $234,744(25.61)$ \\
\hline$[90,99]$ & $12,997(3.77)$ & $4229(2.37)$ & $3416(3.32)$ & $2686(2.97)$ & $3924(4.85)$ & $4524(6.49)$ & $3336(6.73)$ & $35,111(3.83)$ \\
\hline \multicolumn{9}{|l|}{ MEDEA * index, $n(\%)$} \\
\hline U1 & $63,526(19.67)$ & $25,114(14.90)$ & $14,580(15.20)$ & $13,131(15.64)$ & $11,684(15.91)$ & $9413(15.10)$ & $7344(16.57)$ & $144,792(15.80)$ \\
\hline $\mathrm{U} 2$ & $53,337(16.51)$ & 26,606 (15.79) & 15,239 (15.89) & $13,307(15.85)$ & 11,546 (15.72) & $9563(15.34)$ & $6832(15.41)$ & $136,430(14.88)$ \\
\hline U3 & $51,420(15.92)$ & 28,004 (16.62) & 15,988 (16.67) & $13,976(16.64)$ & 11,928 (16.24) & $9839(15.78)$ & 7068 (15.94) & $138,223(15.08)$ \\
\hline $\mathrm{U} 4$ & 46,598 (14.43) & 28,059 (16.65) & 16,264 (16.96) & 14,066 (16.75) & 11,795 (16.06) & $9726(15.60)$ & $6480(14.62)$ & $132,988(14.51)$ \\
\hline U5 & 37,128 (11.49) & 24,998 (14.83) & 15,109 (15.75) & $13,264(15.79)$ & 11,050 (15.05) & $9290(14.90)$ & $6043(13.63)$ & $116,882(12.75)$ \\
\hline $\begin{array}{l}\text { Number of chronic } \\
\text { diseases, median [IQR] }\end{array}$ & $3[2-5]$ & $6[4-7]$ & $7[5-9]$ & $8[6-10]$ & $8[6-10]$ & $8[6-10]$ & $7[6-10]$ & $6[4-8]$ \\
\hline \multicolumn{9}{|l|}{$\begin{array}{c}\text { Number of chronic } \\
\text { diseases (categories), } n(\%)\end{array}$} \\
\hline 0 & $25,380(7.36)$ & $0(0)$ & $0(0)$ & $0(0)$ & $0(0)$ & $0(0)$ & $0(0)$ & $25,380(2.77)$ \\
\hline 1 & 37,626 (10.91) & $45(0.03)$ & $121(0.12)$ & $42(0.05)$ & $36(0.04)$ & $40(0.06)$ & $244(0.49)$ & $38,154(4.16)$ \\
\hline$[2,5)$ & $176,529(51.17)$ & $50,912(28.53)$ & 12,934 (12.59) & 7896 (8.75) & $7990(9.88)$ & $6133(8.8)$ & 6441 (12.99) & $268,836(29.33)$ \\
\hline$[5,10)$ & 99,930 (28.97) & $114,840(64.35)$ & 67,586 (65.78) & $58,154(64.41)$ & $51,082(63.18)$ & $42,058(60.32)$ & 30,059 (60.61) & 463,709 (50.59) \\
\hline$\geq 10$ & 5493 (1.59) & $12,660(7.09)$ & $22,109(21.52)$ & $24,195(26.8)$ & $21,747(26.9)$ & 21,489 (30.82) & $12,847(25.91)$ & $120,540(13.15)$ \\
\hline
\end{tabular}


Table A4. Cont.

\begin{tabular}{|c|c|c|c|c|c|c|c|c|}
\hline & 1. Non-Specific & 2. Diabetes & $\begin{array}{l}\text { 3. Neurological and } \\
\text { Musculoskeletal, } \\
\text { Female Dominant }\end{array}$ & $\begin{array}{c}\text { 4. Behavioral, } \\
\text { Neurological, and } \\
\text { Musculoskeletal, } \\
\text { Female Dominant }\end{array}$ & $\begin{array}{l}\text { 5. Cardio- } \\
\text { Cerebrovascular } \\
\text { and Renal }\end{array}$ & $\begin{array}{l}\text { 6. Cardiovascular, } \\
\text { Renal, } \\
\text { Inflammatory, and } \\
\text { Respiratory }\end{array}$ & 7. Multisystem & $\begin{array}{l}\text { Study Population } \\
\text { (All) }\end{array}$ \\
\hline $\begin{array}{l}\text { Number of medications, } \\
\text { median [IQR] }\end{array}$ & $2[0-3]$ & $5[3-7]$ & $6[4-8]$ & $6[5-9]$ & $7[5-9]$ & $7[5-10]$ & $6[4-9]$ & $4[2-7]$ \\
\hline \multicolumn{9}{|l|}{$\begin{array}{l}\text { Number of medications, } \\
\quad \text { (categories) }, n(\%)\end{array}$} \\
\hline 0 & $113,702(32.96)$ & $536(0.3)$ & $1414(1.38)$ & $132(0.15)$ & $24(0.03)$ & $180(0.26)$ & $1801(3.63)$ & 117,789 (12.85) \\
\hline$[2,5)$ & $127,492(36.96)$ & 67,366 (37.75) & 28,777 (28.01) & 20,597 (22.81) & $12,615(15.6)$ & $10,692(15.34)$ & 10,904 (21.99) & $278,442(30.38)$ \\
\hline$[5,10)$ & $50,510(14.64)$ & 90,914 (50.94) & $55,102(53.63)$ & $52,401(58.04)$ & $47,710(59.01)$ & 38,927 (55.83) & $25,494(51.41)$ & $361,058(39.39)$ \\
\hline$\geq 10$ & $2560(0.74)$ & $14,410(8.07)$ & 14,401 (14.02) & 15,875 (17.58) & $19,924(24.64)$ & $19,318(27.71)$ & $10,029(20.22)$ & $96,518(10.53)$ \\
\hline $\begin{array}{c}\text { Number of visits 2012, } \\
\text { median [IQR] }\end{array}$ & $6[2-10]$ & $10[6-16]$ & 12 [7-18] & 12 [7-19] & 14 [8-23] & 18 [10-29] & 13 [7-23] & 9 [5-16] \\
\hline \multicolumn{9}{|l|}{$\begin{array}{l}\text { Number of visits } 2012 \\
\quad \text { (categories), } n(\%)\end{array}$} \\
\hline 1 & 25,389 (7.36) & 3155 (1.77) & $1463(1.42)$ & $1213(1.34)$ & $1026(1.27)$ & $683(0.98)$ & $954(1.92)$ & $33,884(3.7)$ \\
\hline$[2,5)$ & $75,895(22)$ & $20,685(11.59)$ & 9889 (9.62) & 8168 (9.05) & $6708(8.3)$ & $4336(6.22)$ & $4759(9.6)$ & 130,439 (14.23) \\
\hline$[5,10)$ & $101,438(29.41)$ & $56,518(31.67)$ & $27,564(26.83)$ & $22,805(25.26)$ & 18,077 (22.36) & 11,938 (17.12) & $11,008(22.2)$ & 249,349 (27.2) \\
\hline$\geq 10$ & $97,283(28.2)$ & $97,274(54.51)$ & 63,197 (61.51) & $57,783(64)$ & $54,802(67.78)$ & 52,558 (75.38) & $32,105(64.74)$ & $455,002(49.64)$ \\
\hline
\end{tabular}

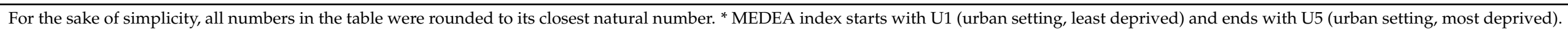

Individuals in rural settings are classified in the variable R. MEDEA index $n=851,564$. 


\section{References}

1. The World Bank. Life Expectancy at Birth, Total (Years). Available online: https://data.worldbank.org/indicator/SP.DYN.LE00. IN (accessed on 10 March 2021).

2. Partridge, L.; Deelen, J.; Slagboom, P.E. Facing up to the global challenges of ageing. Nature 2018, 561, 45-56. [CrossRef] [PubMed]

3. Murray, C.J.L.; Barber, R.M.; Foreman, K.J.; Ozgoren, A.A.; Abd-Allah, F.; Abera, S.F.; Aboyans, V.; Abraham, J.P.; Abubakar, I.; Abu-Raddad, L.J.; et al. Global, regional, and national disability-adjusted life years (DALYs) for 306 diseases and injuries and healthy life expectancy (HALE) for 188 countries, 1990-2013: Quantifying the epidemiological transition. Lancet 2015, 386, 2145-2191. [CrossRef]

4. Strom, B.L.; Kimmel, S.E.; Hennessy, S. (Eds.) Basic principles of clinical pharmacology relevant to pharmacoepidemiologic studies. In Pharmacoepidemiology, 5th ed.; John Wiley \& Sons: Hoboken, NJ, USA, 2011; pp. 23-37.

5. MacMahon, S.; Calverley, P.; Chaturvedi, N.; Chen, Z.; Corner, L.; Davies, M.; Ezzati, M.; Guthrie, B.; Hanson, K.; Jha, V.; et al. Multimorbidity: A Priority for Global Health Research; The Academy of Medical Sciences: London, UK, 2018 ; p. 6.

6. Cahir, C.; Fahey, T.; Teeling, M.; Teljeur, C.; Feely, J.; Bennett, K. Potentially inappropriate prescribing and cost outcomes for older people: A national population study. Br. J. Clin. Pharmacol. 2010, 69, 543-552. [CrossRef] [PubMed]

7. Masnoon, N.; Shakib, S.; Kalisch-Ellett, L.; Caughey, G.E.; Masnoon, N.; Shakib, S.; Kalisch-Ellett, L.; Caughey, G.E. What is polypharmacy? A systematic review of definitions. BMC Geriatr. 2017, 17, 1-10. [CrossRef]

8. Khezrian, M.; McNeil, C.J.; Murray, A.; Myint, P.K. An overview of prevalence, determinants and health outcomes of polypharmacy. Ther. Adv. Drug Saf. 2020, 11. [CrossRef]

9. Thorell, K.; Midlöv, P.; Fastbom, J.; Halling, A. Use of potentially inappropriate medication and polypharmacy in older adults: A repeated cross-sectional study. BMC Geriatr. 2020, 20, 1-9. [CrossRef]

10. Maher, R.L.; Hanlon, J.; Hajjar, E.R. Clinical consequences of polypharmacy in elderly. Expert Opin. Drug Saf. 2013, 13, 57-65. [CrossRef] [PubMed]

11. Wastesson, J.W.; Morin, L.; Tan, E.; Johnell, K. An update on the clinical consequences of polypharmacy in older adults: A narrative review. Expert Opin. Drug Saf. 2018, 17, 1185-1196. [CrossRef] [PubMed]

12. Cullinan, S.; O'Mahony, D.; O'Sullivan, D.; Byrne, S. Use of a frailty index to identify potentially inappropriate prescribing and adverse drug reaction risks in older patients. Age Ageing 2015, 45, 115-120. [CrossRef]

13. Leelakanok, N.; Holcombe, A.L.; Lund, B.C.; Gu, X.; Schweizer, M. Association between polypharmacy and death: A systematic review and meta-analysis. J. Am. Pharm. Assoc. 2017, 57, 729-738. [CrossRef]

14. Gutiérrez-Valencia, M.; Herce, P.A.; Lacalle-Fabo, E.; Escámez, B.C.; Veloz, B.A.C.; Martínez-Velilla, N. Prevalencia de polifarmacia y factores asociados en adultos mayores en España: Datos de la Encuesta Nacional de Salud 2017. Med. Clin. 2019, 153, 141-150. [CrossRef]

15. Forslund, T.; Carlsson, A.C.; Ljunggren, G.; Ärnlöv, J.; Wachtler, C. Patterns of multimorbidity and pharmacotherapy: A total population cross-sectional study. Fam. Pr. 2020, 38, 132-139. [CrossRef] [PubMed]

16. Villén, N.; Guisado-Clavero, M.; Fernández-Bertolín, S.; Troncoso-Mariño, A.; Foguet-Boreu, Q.; Amado, E.; Pons-Vigués, M.; Roso-Llorach, A.; Violán, C. Multimorbidity patterns, polypharmacy and their association with liver and kidney abnormalities in people over 65 years of age: A longitudinal study. BMC Geriatr. 2020, 20, 1-13. [CrossRef]

17. Prados-Torres, A.; Calderón-Larrañaga, A.; Hancco-Saavedra, J.; Poblador-Plou, B.; Akker, M.V.D. Multimorbidity patterns: A systematic review. J. Clin. Epidemiol. 2014, 67, 254-266. [CrossRef]

18. McCarthy, C.; Moriarty, F.; Wallace, E.; Smith, S.M.; Barbara Clyne for the SPPiRE Study Team. The evolution of an evidence based intervention designed to improve prescribing and reduce polypharmacy in older people with multimorbidity and significant polypharmacy in primary care (SPPiRE). J. Comorb. 2020, 10, 32974211. [CrossRef]

19. Chang, T.I.; Park, H.; Kim, D.W.; Jeon, E.K.; Rhee, C.M.; Kalantar-Zadeh, K.; Kang, E.W.; Kang, S.-W.; Han, S.H. Polypharmacy, hospitalization, and mortality risk: A nationwide cohort study. Sci. Rep. 2020, 10, 1-9. [CrossRef]

20. Wolfram. Fuzzy Clustering. Available online: https://reference.wolfram.com/legacy/applications/fuzzylogic/Manual/12.html (accessed on 31 July 2021).

21. Statistical Institute of Catalonia. Population on 1 January. Provinces. Available online: https://www.idescat.cat/pub/?id=aec\& $\mathrm{n}=245 \& l a n g=e n$ (accessed on 3 March 2021).

22. Royal Decree-Law 16/2012, of April 20th, Regarding Urgent Measures to Guarantee the Sustainability of the National Health System and to Improve the Quality and Security of its Provisions. Available online: https://www.boe.es/eli/es/rdl/2012/04/20 /16 (accessed on 4 March 2021).

23. Catalan Health Institute. The CHI. Available online: http:/ / ics.gencat.cat/es/lics/ (accessed on 4 March 2021).

24. García-Gil, M.D.M.; Hermosilla, E.; Prieto-Alhambra, D.; Fina, F.; Rosell, M.; Ramos, R.; Rodriguez, J.; Williams, T.; van Staa, T.; Bolibar, B. Construction and validation of a scoring system for the selection of high-quality data in a Spanish population primary care database (SIDIAP). J. Innov. Health Inform. 2011, 19, 135-145. [CrossRef]

25. Calderón-Larrañaga, A.; Vetrano, D.L.; Onder, G.; Feliu, L.A.G.; Coscollar-Santaliestra, C.; Carfí, A.; Pisciotta, M.S.; Angleman, S.; Melis, R.J.; Santoni, G.; et al. Assessing and measuring chronic multimorbidity in the older population: A proposal for its operationalization. J. Gerontol. Ser. A 2016, 72, 1417-1423. [CrossRef] 
26. World Health Organization. The Anatomical Therapeutic Chemical Classification System with Defined Daily Doses (ATC/DDD). Available online: https:/ / www.who.int/classifications/atcddd/en/ (accessed on 9 March 2021).

27. UpToDate. Available online: https://www.uptodate.com/contents/search (accessed on 15 March 2021).

28. BOT PLUS. Available online: https:/ / botplusweb.portalfarma.com/botplus.aspx (accessed on 2 March 2021).

29. CIMA. Available online: https:/ / cima.aemps.es/cima/publico/home.html (accessed on 3 March 2021).

30. Borrell, C.; Cano-Serral, G.; Esnaola, S.; Nolasco, A.; Pasarín, M.I.; Ramis, R.; Saurina, C.; Escolar-Pujolar, A. Constructing a deprivation index based on census data in large Spanish Cities. Gac. Sanit. 2008, 22, 179-187.

31. Karlis, D.; Saporta, G.; Spinakis, A. A simple rule for the selection of principal components. Commun. Stat. Theory Methods 2003, 32, 643-666. [CrossRef]

32. Bezdek, J.C.; Ehrlich, R.; Full, W. FCM: The fuzzy c-means clustering algorithm. Comput. Geosci. 1984, 10, 191-203. [CrossRef]

33. Zhao, Q. Cluster Validity in Clustering Methods. Ph.D. Thesis, University of Eastern Finland, Joensuu, Finland, 25 June 2012.

34. Violán, C.; Roso-Llorach, A.; Foguet-Boreu, Q.; Guisado-Clavero, M.; Pons-Vigués, M.; Pujol-Ribera, E.; Valderas, J.M. Multimorbidity patterns with K-means nonhierarchical cluster analysis. BMC Fam. Pr. 2018, 19, 1-11. [CrossRef]

35. Violán, C.; Foguet-Boreu, Q.; Fernández-Bertolín, S.; Guisado-Clavero, M.; Cabrera-Bean, M.; Formiga, F.; Valderas, J.M.; RosoLlorach, A. Soft clustering using real-world data for the identification of multimorbidity patterns in an elderly population: Cross-sectional study in a Mediterranean population. BMJ Open 2019, 9, e029594. [CrossRef]

36. Vetrano, D.L.; Roso-Llorach, A.; Fernández, S.; Guisado-Clavero, M.; Violán, C.; Onder, G.; Fratiglioni, L.; Calderón-Larrañaga, A.; Marengoni, A. Twelve-year clinical trajectories of multimorbidity in a population of older adults. Nat. Commun. 2020, 11, 1-9. [CrossRef]

37. Violán, C.; Foguet-Boreu, Q.; Flores-Mateo, G.; Salisbury, C.; Blom, J.; Freitag, M.; Glynn, L.; Muth, C.; Valderas, J.M. Prevalence, determinants and patterns of multimorbidity in primary care: A systematic review of observational studies. PLoS ONE 2014, 9 , e102149. [CrossRef]

38. Chobot, A.; Górowska-Kowolik, K.; Sokołowska, M.; Jarosz-Chobot, P. Obesity and diabetes-Not only a simple link between two epidemics. Diabetes Metab. Res. Rev. 2018, 34, e3042. [CrossRef]

39. Becker, C.; Schneider, C.; Aballéa, S.; Bailey, C.; Bourne, R.; Jick, S.; Meier, C. Cataract in patients with diabetes mellitus-Incidence rates in the UK and risk factors. Eye 2018, 32, 1028-1035. [CrossRef] [PubMed]

40. Giovannucci, E.; Harlan, D.M.; Archer, M.C.; Bergenstal, R.M.; Gapstur, S.M.; Habel, L.; Pollak, M.; Regensteiner, J.G.; Yee, D. Diabetes and cancer: A consensus report. Diabetes Care 2010, 33, 1674-1685. [CrossRef]

41. Angum, F.; Khan, T.; Kaler, J.; Siddiqui, L.; Hussain, A. The prevalence of autoimmune disorders in women: A narrative review. Cureus 2020, 12, e8094. [CrossRef] [PubMed]

42. Chen, W.; Thomas, J.; Sadatsafavi, M.; FitzGerald, J.M. Risk of cardiovascular comorbidity in patients with chronic obstructive pulmonary disease: A systematic review and meta-analysis. Lancet Respir. Med. 2015, 3, 631-639. [CrossRef]

43. Iseme, R.; McEvoy, M.; Kelly, B.; Agnew, L.; Walker, F.R.; Handley, T.; Oldmeadow, C.; Attia, J.; Boyle, M. A role for autoantibodies in atherogenesis. Cardiovasc. Res. 2017, 113, 1102-1112. [CrossRef] [PubMed]

44. Mathieu, S.; Couderc, M.; Tournadre, A.; Soubrier, M. Cardiovascular profile in osteoarthritis: A meta-analysis of cardiovascular events and risk factors. Jt. Bone Spine 2019, 86, 679-684. [CrossRef] [PubMed]

45. Bora, D.J.; Gupta, A.K. A Comparative study between fuzzy clustering algorithm and hard clustering algorithm. Int. J. Comput. Trends Technol. 2014, 10, 108-113. [CrossRef]

46. Everitt, B.; Landau, S.; Leese, M. Cluster Analysis, 5th ed.; Balding, D.J., Cressie, N.A., Fitzmaurice, G.M., Goldstein, H., Eds.; John Wiley \& Sons: Hoboken, NJ, USA, 2011.

47. Muth, C.; Blom, J.W.; Smith, S.; Johnell, K.; Gonzalez-Gonzalez, A.I.; Nguyen, T.S.; Brueckle, M.; Cesari, M.; Tinetti, M.E.; Valderas, J.M. Evidence supporting the best clinical management of patients with multimorbidity and polypharmacy: A systematic guideline review and expert consensus. J. Intern. Med. 2018, 285, 272-288. [CrossRef]

48. Ng, S.K.; Tawiah, R.; Sawyer, M.; Scuffham, P. Patterns of multimorbid health conditions: A systematic review of analytical methods and comparison analysis. Int. J. Epidemiol. 2018, 47, 1687-1704. [CrossRef] 